\title{
Spinal Osteophytosis: An Uncommon Cause of Dysphagia
}

\author{
Andreia De Matos ${ }^{a, b}$ Cristiane Macedo ${ }^{a}$ Patrícia Afonso Mendes ${ }^{a, b}$ \\ ${ }^{a}$ Internal Medicine, Coimbra Hospital and University Center, Coimbra, Portugal; ${ }^{b}$ Clinical Medicine, Faculty of \\ Medicine, University of Coimbra, Coimbra, Portugal
}

Keywords

Spinal osteophytosis · Oropharyngeal dysphagia

\section{Osteofitose Cervical: Uma Causa Incomum de Disfagia}

\section{Palavras Chave}

Osteofitose cervical · Disfagia orofaríngea

A Caucasian 60-year-old man, with a career in housebuilding, presented with mild, chronic and progressive dysphagia, manifested by difficulty in swallowing solid food for the last 6 months. He had no cervical pain, weight loss, dysphonia, respiratory complaints, previous surgical intervention, radiotherapy, major trauma, myogenic or metabolic known causes for this symptom. The patient had a normal cervical and chest physical examination and neurologic exam. A barium swallow test was firstly performed, revealing a posterior esophagus indentation due to an osteophyte formation, which interfered with contrast progression. This exam also ruled out dysfunction in motility or a Zenker's diverticulum. Consequently, to better characterize the osteoarticular disease, the patient was submitted to a computed tomography (CT) and cervical magnetic resonance imaging (MRI) which revealed degenerative changes such as: anterior and lateral protru-

karger@karger.com www.karger.com/pjg

Karger"

GOPEN ACCESS
(C) 2021 Sociedade Portuguesa de Gastrenterologia. Published by S. Karger AG, Basel

This is an Open Access article licensed under the Creative Commons Attribution-NonCommercial-4.0 International License (CC BY-NC) (http://www.karger.com/Services/OpenAccessLicense), applicable to the online version of the article only. Usage and distribution for commercial purposes requires written permission. sion of vertebral discus, osteophytes from C3 to C5, uncarthrosis, and posterior C3 to C6 interapophysary hypertrophic arthrosis, without ligament calcification or cervical webs (Fig. 1a-c). Finally, upper digestive endoscopy ruled out intrinsic abnormalities, and cervical ultrasound was also normal.

Cervical osteophytes occur in $20-30 \%$ of the general population [1] and are mostly associated with diffuse idiopathic skeletal hyperostosis and ankylosing spondylitis [2]. Most osteophytes of the anterior margin of the cervical spine are asymptomatic. Nevertheless, cervical osteophytes were the cause of dysphagia in $11.7 \%$ of a studied population, with a mean age of $79 \pm 8$ years $[3,4]$, disclosing a possible underrecognized etiology. In this matter, according to Lee et al. [5], patients with this condition were usually men ( $81 \%)$, with a mean age of 68 years and the C3 to C6 level most commonly involved, typically presenting with a long history of dysphagia. Other symptoms include food impaction, dysphonia and respiratory obstruction $[2,3]$. The diagnostic imaging approach includes a lateral X-ray, barium swallow, and cervical CT or MRI. Surgical approach may be a definite solution, but diet restrictions may cause satisfactory improvement [1$3,5]$. Our patient was paucisymptomatic and remains only with adapted diet. The authors highlight anterior cervical osteophytosis as a differential diagnosis of oropharyngeal dysphagia. 

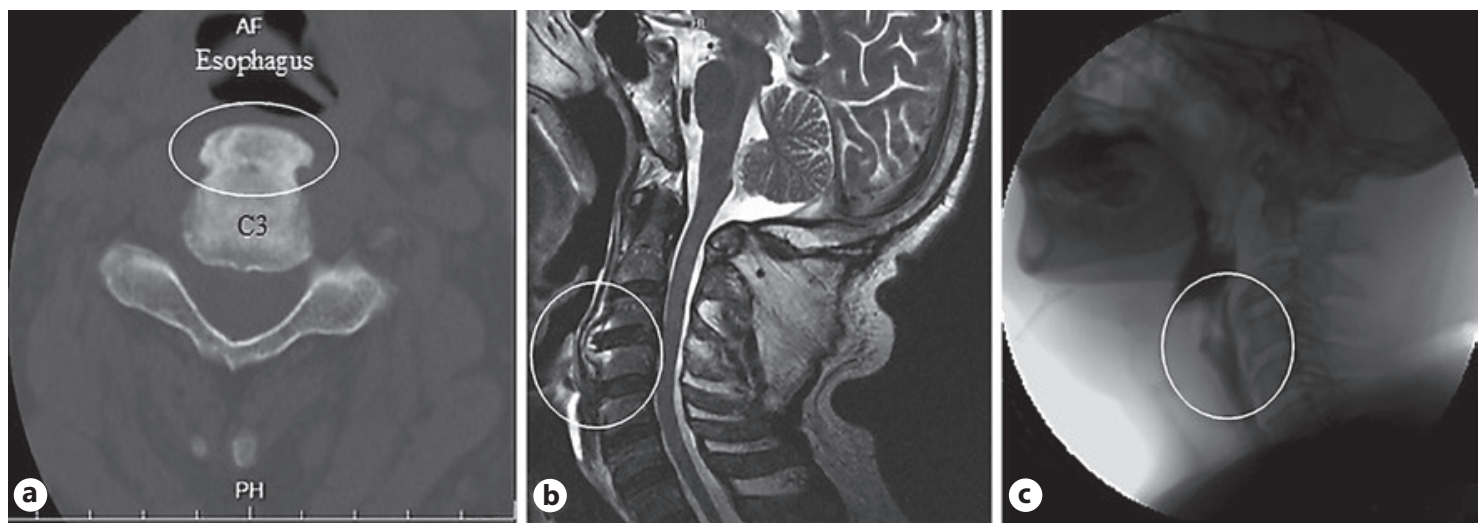

Fig. 1. a C3 somatic marginal osteophyte (white circle) on CT. b Cervical MRI with anterior and lateral protrusion of the vertebral discus and osteophytes in C3 to C5. c Barium swallows with posterior esophagus indentation at the level of the osteophyte formation.

\section{Statement of Ethics}

The authors stated that the subject gave informed consent to publish this case.

\section{Conflict of Interest Statement}

The authors have no conflicts of interest to declare.

\section{Funding Sources}

No funding was received.

\section{Author Contributions}

All authors contributed equally to data acquisition, writing and approval of the final version of the paper and agreed for all aspects of the work in ensuring that questions related to the accuracy or integrity of any part of the work were appropriately investigated and resolved.

\section{References}

1 Akbal A, Kurtaran A, Selcuk B, Gurcan A, Ersoz M, Akyuz M. The development of dysphagia and dysphonia due to anterior cervical osteophytes. Rheumatol Int. 2009 Jan;29(3): $331-4$.

2 Makaram N, Gohil R, Majumdar S. Dysphagia due to oesophageal obstruction: A case report of unusual occupational aetiology. Ann Med Surg (Lond). 2015 Nov;4(4):438-43.
3 Giger R, Dulguerov P, Payer M. Anterior cervical osteophytes causing dysphagia and dyspnea: an uncommon entity revisited. Dysphagia. 2006 Oct;21(4):259-63.

4 Hee Eun Choi, et al. Characteristics and Clinical Course of Dysphagia Caused by Anterior Cervical Osteophyte. Ann Rehabil Med. 2019 Feb; 43(1):27-37. https://doi.org/10.5535/ arm.2019.43.1.27.
5 Lee, Seung Ah, MD; Kim, Kyung Eun, MD; Paik, Nam-Jong, MD, PhD Dysphagia caused by multilevel cervical osteophytes. Am J Phys Med Rehabil. 2008 Jul;87(7):607. https://doi. org/10.1097/PHM.0b013e31817c496b. 